\title{
Martín Sarmiento y los estudios orientales: La edición de la Bibliotheca Arabico-Hispana de Casiri
}

\author{
Concha VARELA-OROL \\ Universidad da Coruña. Grupo de Investigación A Herdanza da Ilustración \\ concepcion.varela@udc.es
}

Recibido: Septiembre 2011

Aceptado: Junio 2012

Resumen: El objeto de este trabajo es estudiar la contribución de Martín Sarmiento en el primer proyecto llevado adelante en España en el siglo XVIII para relanzar los estudios árabes, la catalogación de los manuscritos árabes del Escorial realizada por Miguel Casiri. Esta contribución se analiza en un doble nivel: su aportación a la fundamentación ideológica del proyecto como parte de su reflexión sobre la construcción de una memoria nacional, base de la creación del estado moderno, y su reflexión sobre los aspectos operativos que debían ponerse en marcha para la realización de la obra de Casiri.

Palabras clave: Martín Sarmiento; Miguel Casiri; Estudios orientales; Siglo XVIII; Manuscritos árabes; Catalogación de manuscritos; Biblioteca de El Escorial; Biblioteca Nacional de España.

\section{Martin Sarmiento and Oriental studies: the edition of Casiri's Bibliotheca Arabica-Hispana}

\begin{abstract}
The purpose of this paper is to study the contribution of Martin Sarmiento in the first project carried forward in Spain during the $18^{\text {th }}$ century (Eighteenth Century, Enlightenment) to revive Arabic studies, the catalogue of the Arabic manuscripts of the Escorial by Miguel Casiri. This contribution is analysed in two ways: his assessment to the ideological framework of the project as part of his reflection about the construction of a national memory, constituent element on the creation of the modern state, and his consideration on the operational issues that should be implemented to carry out the work of Casiri.
\end{abstract}

Keywords: Martín Sarmiento; Miguel Casiri; Oriental studies; $18^{\text {th }}$ century (Eighteenth Century, Enlightenment); Arabic manuscripts; Cataloguing of manuscripts; Escorial Library; Biblioteca Nacional (Spain). 
Mi mayor está en el Escorial a divertirse i acompañar a un escriviente syro de esta bibliotheca; el qual va a reconocer los libros orientales que ai en aquella i ver la utilidad pública que de ellos se puede seguir.

Carta de Manuel Martínez Pingarrón a Gregorio Mayans, 10 de mayo de 1749

\section{INTRODUCCIÓN}

Los intentos llevados a cabo a mediados del siglo XVIII para recuperar las fuentes manuscritas que permitiesen abordar la elaboración de una historia crítica de España, ligada a la construcción de una identidad nacional basada en la lengua y el pasado común, fueron la base para un renacimiento de los estudios orientales, confinados hasta entonces en las órdenes religiosas y en un interés en clave teológica o misionera. En el impulso a estos estudios que encontramos en las Luces juegan un papel de primer orden como impulsor Martín Sarmiento y como factor el maronita Miguel Casiri, a quien encarga Rávago la elaboración del catálogo de manuscritos árabes de la Biblioteca del Escorial.

Ciertamente en el proyecto de llevar adelante la catalogación y estudio de las fuentes árabes confluyeron muchos otros hombres de letras del momento, entre los que hay que destacar a Gregorio Mayans, Martínez Pingarrón, Burriel, Cornide y algunos otros, y en este sentido Sarmiento, inspirado sin duda por los trabajos que habían llevado adelante maurinos y bolandistas, no dejará de advertir que es preciso aquí una obra colectiva, porque "Proyecto en el cual no conspiran, y con gusto, todos los que le han de abrazar jamás pasará de la llama transitoria".

Como es conocido, Sarmiento actúa en numerosas ocasiones como asesor del confesor real; estaba junto con Mayans ${ }^{1}$ y Juan de Santander en el círculo más próximo de Rávago, como señala Martínez Pingarrón: “... porque he sabido (no sé si será cierto) que el P. Confesor consulta con Vmd. muchas cosas, de suerte que Vmd. i el P. Sarmiento, me han dicho, son sus consultores i Santander a quien, parece, quiere mucho" (Mayans i Siscar, Epistolario, 7, 1, 362-364). Esta posición hace que Sarmiento juegue un papel importante como ideólogo y asesor en los proyectos culturales llevados a cabo en España a mediados del siglo XVIII. Pero lo hará también, a un nivel más operativo, a través de las relaciones que mantiene

${ }^{1}$ También Mayans intervino en la revisión de la Bibliotheca Arabico-Hispana de Casiri, quien señala que fue el bibliotecario mayor Juan de Santander quien envió la obra al valenciano, indicando que en una carta "amistosísima" le envió las correcciones y anotaciones de ambos tomos (Casiri, 2, n. pág.) Por el contrario, un texto de Mayans sobre la Historia del moro Rasis no fue incluido debido a su longitud, aunque si se hizo un elogio del mismo en el T.2 de la Bibliotheca. (Mestre, 381). 
con algunas otras figuras de primera línea de la puesta en marcha de la política cultural española, entre ellas Miguel Casiri.

El objeto de este trabajo es estudiar ambas contribuciones de Martín Sarmiento en el primer proyecto llevado adelante en España en el siglo XVIII para relanzar los estudios árabes, la catalogación de los manuscritos árabes del Escorial. Para ello emplearemos como fuente fundamental las cartas-informe enviadas por Sarmiento a Rávago en relación a la obra de Casiri, así como la correspondencia con éste, reunidas en la copia de la colección de Medinasidonia bajo el título Sobre los códices orientales de la Real Biblioteca del Escorial. ${ }^{2}$

\section{LA BIBLIOTECA ORIENTAL DE SARMIENTO}

El interés de Sarmiento en los estudios orientales es patente a través del conjunto de su obra, sea esta de carácter histórico, filológico, educativo, de historia natural, biblioteconómica, etc., alentando siempre la conveniencia de los estudios de la lengua árabe, sin la cual sería imposible adelantar no sólo en la elaboración de la historia medieval de España, sino también en la filología, agricultura, geografía, cronología, medicina, matemáticas, así como en los estudios hebreos y bíblicos (Sarmiento, Carta a Esteban de Terreros). Él mismo en Sobre los códices indica a Rávago que estos textos junto con las Reflexiones literarias (Sarmiento, Reflexiones) y el Catálogo para formar una librería curiosa (Sarmiento, Catálogo para formar), forman una "obrilla uniforme" que trataría de "providencias sobre la promoción de la literatura en España", es decir de la cultura en España, que para Sarmiento es siempre base de su desarrollo.

$\mathrm{Su}$ interés por la lectura de los textos orientales parece haber comenzado muy pronto, ya que confiesa haberse dedicado en su estancia en 1715 en el Colegio San Vicente de Salamanca a copiar los 40 alfabetos orientales de la obra de Ambrogio Teseo Introductio in Chaldaicam linguam, Syriacam atque Armenicam \& decem alias linguas. Characterum differentium alphabeta, circiter quadraginta, \& eorundem inuicem conformatio (1539), uno de los primeros estudios en lingüística comparada. Y el año anterior en la biblioteca de San Martín de Madrid había

${ }^{2}$ Tal y como aparece dispuesto en la copia de la Colección de Medinasidonia (Sarmiento, Sobre los códices) el texto consta de: 1/Carta-informe de Sarmiento a Rávago, 6/2/1750 (fol. 53-68); 2/Carta-informe de Sarmiento a Rávago, 12/12/1750 (fol. 69-80v.); 3/Carta de Sarmiento a Rávago remitiéndole el texto 2/, 18/12/1750 (fol. 81-82); 4/Copia de carta a Miguel Casiri, 17/7/1751(fol. 83-84); 5/Índice de las Reflexiones literarias y de las cartas a Rávago sobre los manuscritos del Escorial (fol. 85-92). A estos textos siguen, claramente separados en la copia, dos cartas de 1749 de Sarmiento a Rávago sobre publicación de códices..., etc. e Imprenta Real (fol. 95-105). Los textos señalados van precedidos de las Reflexiones literarias (fol. 3-50v.), y seguidos del Catálogo de libros selectos, aquí con el título Catálogo para formar una librería curiosa (fol.107-181). 
copiado los alfabetos de "las lenguas Griega, Hebrea, Chaldea, Rabinica, Syrica, Arabiga, Ghotica, etc." (Sarmiento, Catálogo de los pliegos).

En 1718 cita como principales trabajos la copia y extractos de diversos libros que tuvo prestados: la Bibliothèque orientale ou dictionnaire universel contenant tout ce qui regarde la connoissance des peuples de l'Orient, del orientalista francés Barthélemy d'Herbelot, publicada después de la muerte de su autor por Antoine Galland, el traductor de las Mil y una noches, que se convertirá en el texto sobre el mundo islámico que tendrá más importancia en Europa en el siglo XVIII, y la Bibliotheca Magna Rabinica de Giulio Bartoloccio, una bibliografía de la literatura hebrea y una presentación de su cultura. Otro autor citado por Sarmiento es el maronita Giuseppe Assemani. Por estos años Sarmiento no poseía estas obras en su biblioteca, sino que las consulta, además de en la del Colegio de San Vicente de Salamanca, en la biblioteca de su monasterio de San Martín de Madrid, pero seguramente no tardará mucho en adquirirlas. De la obra de Herbelot, de gran influencia en toda Europa durante siglo y medio, incorpora a sus libros la primera edición de 1697, añadiendo en su catálogo esta nota: "es un thesoro y ya muy raro".

Los textos de estudios orientales constituirán el apartado denominado "Erudición oriental" en el Catálogo de su biblioteca (Sarmiento, Catálogo de los autores). Una erudición que por esos mismos años la Encyclopédie francesa (Diderot, 5, 914) consideraba que comprendía tres ramas principales del conocimiento: la historia, incluyendo la historia de las artes y las ciencias, las lenguas, y los libros. Fundamentalmente serán estos tres polos a los que apunten las colecciones sarmentinas.

Sarmiento, en estos primeros años del siglo XVIII, deja ya ver un interés por los estudios orientales que se habían desarrollado en el siglo anterior en muchos países europeos, entre ellos Francia e Italia, representados en sus lecturas. Fruto de ellas es su recopilación de 1718, Pangrammaticon Lexicon sive clavis ómnium alphabetorum novum veterum...(Sarmiento, Pangrammaticon) Posteriormente, sus conocimientos sobre antiguas escrituras le permiten intervenir, a petición del Marqués de Grimaldi, en el asunto de los "hallazgos" en la Alcazaba de Granada a partir de 1752, que reeditaban la vieja polémica de los libros plúmbeos y sus implicaciones en el Voto de Santiago (Razón ${ }^{3}$, 193-96).

Con libros sobre los métodos de escribir y alfabetos abría precisamente la colección de libros de erudición oriental de su biblioteca. Procedían en muchos casos de las imprentas romanas de la Congregación Propaganda Fide, encargada de organizar la labor misionera de la iglesia, y cuyas prensas poseían caracteres de distintas lenguas, entre ellos los árabes, y se empleaban en la edición de obras para la difusión de la fe. Procedentes también de estas prensas y de otras imprentas árabes europeas poseía Sarmiento las más importantes gramáticas y diccionarios

\footnotetext{
${ }^{3}$ Sempere y Guarinos atribuye la obra a Pérez Bayer.
} 
de lenguas orientales, como la de Francesco María Maggio del georgiano, árabe y turco; las gramáticas árabes de Erpenius y Francesco Martelotto, la gramática árabigo-morisca de Pedro de Alcalá, el diccionario árabe-italiano de Domingo Germano de Silesia, el léxico del discípulo de Erpenius Jacob Golius y el de Antonio Giggeio, estos dos diccionarios fundamentales para Sarmiento (Sarmiento, Sobre los códices, 69-80v).

A estas obras siguen otras de historia (Eutychius, Giorgio Elmacino, Pocock, Abulpharagio), de historia de la ciencia, especialmente de la astronomía (Ulugh Beg, Gravius, Alfragani), y catálogos o "bibliotecas", donde además de la obras de Herbelot, están los cuatro volúmenes publicados de la Bibliotheca Orientalis Clementino-Vaticana... (1719-1728) de Assemani, el primer volumen del catálogo de los códices manuscritos de la Biblioteca Real de París editado en 1739, que correspondía a los manuscritos orientales y que le servirá a Sarmiento de punto de comparación con el catálogo de Casiri, como veremos; el catálogo de códices manuscritos, "y ay muchos orientales", de la biblioteca del emperador en Viena realizado por Nessel (1690) que continuaba el catálogo de esta biblioteca realizado por Lambecius, y el de la Biblioteca Vaticana publicado en 1591 por Angelo Roccha. También está en estos estantes la edición del Corán de Marraccio, con la refutación del mismo.

A continuación figuran las referencias de las obras de los más importantes orientalistas europeos del siglo XVII, separadas bajo los epígrafes de su nombre. Encontramos los textos de los miembros de la dinastía de hebraístas bajo "Buxtorfios", las obras de Hottinger, cuya Bibliotheca orientalis incluía el índice de libros arábigos del morisco Alonso del Castillo, Selden, Vossius, padre e hijo, y el orientalista holandés Adrian Reland, que había reivindicado el estudio del Islam en sus propias fuentes.

Ciertamente el apartado de su biblioteca bajo la denominación "Erudición oriental", no es de los más numerosos, ya que reúne 64 registros de obras, por supuesto también de hebraísmo. Pero no debía ser fácil obtener estos libros en España, si tenemos en cuenta que Martínez Pingarrón se queja a Mayans en 1750 de no encontrar una gramática arábiga en Madrid (Mayans i Siscar, Epistolario, 7 , 1, 330-331). De hecho, en muchos de los registros bibliográficos Sarmiento indica que se trata de libros raros, muy raros, o "raro y muy caro". Por otra parte, entre los registros hay algunas referencias a otros apartados de su biblioteca, como en el caso del Nuevo Testamento arábigo del orientalista holandés Thomas Erpenio, ubicado entre sus colecciones bíblicas. Esta ubicación separada del conjunto de los fondos bíblicos hebraístas y arabistas puede ser leída como muestra del desplazamiento del interés teológico que había caracterizado estos estudios en España hacia una reflexión que atendía especialmente a la cultura, como base de la construcción nacional, señalado por Aurora Rivière (Rivière Gómez, 2000: 25-26).

En todo caso, la importancia de las fuentes librarias parece haber sido fundamental en la formación de Sarmiento en este terreno, ya que, de acuerdo a su 
propio testimonio, no poseía grandes conocimientos de la lengua arábiga, de la que dice conocer solamente los caracteres muy superficialmente, por lo que advierte a Rávago que la información que le proporciona es "de tal qual especie vaga que he leído en uno, u otro Libro de Erudición Oriental" (Sarmiento, Sobre los códices, 80$)^{4}$

\section{UN PROYECTO DE ESTUDIOS ÁRABES}

Como es conocido el maronita Miguel Casiri llega a Madrid en 1748 a solicitud de Rávago, que había sido su profesor en Roma y que lo coloca como escribiente en la Biblioteca Real, donde de acuerdo con su testimonio se dedica a los estudios orientales para obtener en el futuro el cargo de Intérprete Real de Lenguas orientales por consejo del confesor real (Bibliotheca, 1,2). Previamente, según relata el propio Sarmiento, había estado en Oriente con Assemani y había colaborado posteriormente con él en la edición vaticana de las obras de San Efrén, iniciada en 1737 por el jesuita y orientalista Pietro Benedetti, para lo que se habían basado en distintos manuscritos siríacos traídos por Assemani y Casiri de su viaje a Oriente en 1735.

Es posible que fuesen los bibliotecarios Nasarre o Santander, o el propio Rávago quien lo pongan en contacto con Sarmiento; en todo caso, el benedictino muestra con claridad la valoración que le merece: “...porque conozco, estimo y aprecio al dicho don Miguel, y venero sus prendas en todo género de literatura oriental..." (Sarmiento, Sobre los códices, 53) Y además se jacta de haber sido él, quien viendo las dotes de Casiri, propone a Rávago "...que le remitiese al Escurial con el fin de reconocer los manuscritos góticos y arábigos de la Librería" (Sarmiento, Catálogo de los pliegos, 5).

Los manuscritos escurialenses habían sido ya objeto de inventarios y catálogos desde el siglo XVI. Inventario era la primera relación que conocemos de estos códices, atribuido a Antonio Gracián y datado en 1572. También es cierto que los fondos árabes se incluían en catálogos de manuscritos posteriores, el más conocido el realizado por Arias Montano, y también se habían redactado catálogos específicos de ellos (Para la formación y catalogación de esta colección véase Justel), entre los que cita Sarmiento el realizado en 1583 por Alonso del Castillo, un morisco que poco después estaría implicado en el asunto de los Libros Plúmbeos del Sacromonte. Pero como es conocido en 1671 la biblioteca había sufrido un importante incendio, en el cual se habían perdido una parte importante de tales manuscritos, y ello hacía necesario proceder a un nuevo catálogo de los mismos. Será Rávago quien encarga a Casiri la realización de la catalogación de los manuscritos árabes

${ }^{4}$ Unos años antes, en 1747, Sarmiento insistía en la misma idea de desconocer la lengua árabe, pero advirtiendo no ser igual no saber la lengua arábiga y no tener erudición arábiga, siendo para esto último suficiente conocer francés, sin duda refiriéndose a la obra de Herbelot (Sarmiento, Nota, 390-96v.) 
del Escorial, donde el maronita está ya en 1749, y a donde parece que viajó dos veces ese mismo año, la segunda acompañado de Nasarre. (Casiri, 1, 2). A finales de enero de 1750 Sarmiento había recibido un borrador de los trabajos realizados por el maronita. Casiri vuelve al Escorial antes de diciembre de 1750, ya que en el 12 de ese mes Sarmiento escribe a Rávago dándole su opinión sobre unos nuevos cuadernos entregados por Casiri por indicación del confesor real. Debe de ser en este viaje donde añade al índice datos sobre la patria del escritor, profesión, edad, escritos, etc. "con el máximo cuidado" (Casiri, 1, 3), ya que Sarmiento informa a Rávago que los trabajos están ahora "más circunstanciados". El maronita volverá al Escorial en mayo de 1752, ya que Santander "considerando que era conveniente una nueva obra" le envía con Martínez Pingarrón para ordenar los manuscritos por facultades (Casiri, 1, 3). Y debió de acudir en otras dos ocasiones, pues en la correspondencia mantenida con objeto de conseguir una plaza para el arabista José Banqueri señala: “...por seis veces he pasado al Escorial a reconocer y extractar dichos libros, tres viajes por seis meses cada viaje, y otros tres por dos y tres meses..."(Soto Pérez, 1985: 108).

Los comentarios al trabajo fruto de las primeras estancias del maronita en el Escorial constituyen el primero de los informes sarmentinos, que supone un programa para poner en marcha los estudios árabes en España. En él Sarmiento pide el desarrollo de acciones en distintos ejes: el incremento de las colecciones de manuscritos árabes y la catalogación de estos fondos existentes en las bibliotecas, el establecimiento de un plan de edición y de una imprenta árabe, y la puesta en marcha de estudios en lenguas orientales. Por tanto, para el benedictino la realización de la Bibliotheca de Casiri se enmarca en un amplio proyecto, donde confluyen los intereses políticos y los culturales.

Él mismo muestra en los informes a Rávago dicha confluencia: en las ventas de manuscritos orientales traídos por ingleses y holandeses en sus viajes, observa Sarmiento que "...se ven unidos el comercio Político, y Literario"; al señalar la necesidad de adicionar la Bibliotheca de Nicolás Antonio después de revisar los manuscritos existentes, dice el benedictino que los que quieren hacerlo de otro modo actúan como libreros en busca del lucro, “...no como literatos y celosos de las glorias de España, y de su literatura" (Sarmiento, Sobre los códices, 59v); el estudio del árabe es imprescindible “...para entender con fundamento muchas voces de la lengua castellana” (Sarmiento, Sobre los códices, 61v); en fin:

Ahora solo falta, y debemos esperar, que Nuestro Monarca no permita que las Artes Prácticas se jacten de que solo ellas merecieron la atención y protección de su Magestad, con exclusión de las Ciencias Especulativas. Tengo ya por un infalible presagio, de que estas se promoverán a toda costa, y comenzarán a florecer en virtud de alguna magnifica empresa literaria, siendo el primer paso que VS ${ }^{a}$ ha dado a este fin; consiguiendo que $D^{n}$ Miguel Casiri pasase a registrar los dichos Manuscritos Arabigos del Escurial, y 
formase el presente Índice de todos ellos (Sarmiento, Sobre los códices, 67).

La finalidad del florecimiento de las letras es expresado así por Sarmiento: “...que jamás estará floreciente, y victorioso un Estado en donde no estuviesen florecientes las Letras, y que casi es quimera, que floreciendo las Artes, Ciencias, y Bellas Letras en un Reino, no sea este, al mismo tiempo feliz en todo lo demás.'(Sarmiento, Sobre los códices, 65).

En el segundo informe a Rávago, después de revisar la nueva redacción del trabajo de Casiri, Sarmiento, además de señalar los más importantes códices incluidos en la Bibliotheca, plantea al confesor real un proyecto más amplio, ya que al observar que pasan de 20 los códices referidos a la Historia literaria de España, en los que se hayan noticias del lugar y cronología de muchos autores españoles, cree que la constitución de un equipo de maronitas bajo la dirección de Casiri permitiría a partir de dichos códices construir una Bibliotheca Arábico-Hispana en dos o tres volúmenes, "que pusiese los nombres, Patrias, escritos y muertes de todos los Autores Árabes Españoles" (Sobre los códices, 73). Este será su principal argumento para oponerse, por prematura, a la reedición de la Bibliotheca de Nicolás Antonio, ya que no será posible perfeccionarla antes de registrar todos los archivos y sus códices para aumentarla y corregirla con "las obras de antiguos españoles escritores, que escribieron en latín, en arábigo, en hebreo, en castellano, y en otros dialectos vulgares" (Sarmiento, Sobre los códices, 59).

Entre estos autores no olvidaba Sarmiento la aportación cultural de las mujeres, ya que en dichos códices no sólo hay noticias de varones, sino también de "muchísimas mujeres Doctas y Escritoras en todo género de Literatura" (Sarmiento, Sobre los códices, 72). Casiri por su parte destacó en la Bibliotheca los nombres de mujeres ilustres contenidas en algunos de estos códices bibliográficos, como el número 1.672 que incluye, después de los nombres de varones, un índice de mujeres sobresalientes en el cultivo de las letras hispánicas, acompañándola de una breve nota biográfica (Casiri, 149-50).

El planteamiento del benedictino indica con claridad que el objetivo de Sarmiento a la hora de establecer un programa de acción para los estudios orientales superaba con mucho el ámbito teológico, enfocado a la crítica y exégesis bíblica, para centrarse en el histórico, y en el filológico, como forma de construcción de una memoria nacional que sirviese a un tiempo como un proyecto de futuro. En este sentido podemos afirmar que Martín Sarmiento puede ser visto como un miembro de los movimientos que, en palabras de Aurora Rivière, se producirían en las últimas décadas del siglo XVIII interesándose por los estudios orientales, un interés que "...derivaba explícita y directamente de la singular significación que,..., tenían en relación con la reflexión nacionalista española, precedente y pareja a la posterior y definitiva configuración del estado nacional contemporáneo" (Rivière, 30). Al mismo tiempo que contribuía a la creación de una identidad nacional reivindicando un glorioso pasado gracias al desarrollo de la 
cultura árabe y su contribución a la cultura europea, se proponía un futuro con grandes empresas culturales comunes, bajo el manto de la monarquía. Como resultado la corona española resultará prestigiada ante las cortes europeas, ya que con el estudio de las lenguas orientales y las imprentas de sus caracteres "...se hará nuestra Nación más expectable, no solo en Europa, sino también en África, y en todo el Oriente. Por las versiones del Arábigo al español sabremos las cosas de los Árabes, y las muchas noticias selectas de nuestra Nación que tienen sepultadas en sus Códices M.S ${ }^{\text {tos }}$. Y por las versiones que en lo futuro se podrán hacer del Español al Árabe les comunicaremos las excelencias de España, y de sus Reyes" (Sarmiento, Sobre los códices, 121).

\subsection{EL INCREMENTO DE LAS COLECCIONES DE MANUSCRITOS ÁRABES}

Sarmiento señala tres medios para realizar la historia de España entre el siglo VIII y el XIII, una historia donde los pseudo-cronicones "solo sirven para afrenta de la Historia de España así Eclesiástica, como Civil". El primer medio es esperar a que un hallazgo fortuito permita desenterrar lápidas, medallas, monedas, inscripciones y libros desconocidos. El segundo es reunir todos los manuscritos dispersos en bibliotecas y archivos españoles. El tercero recurrir a autores árabes y hebreos, para lo que no duda recomendar que se viaje a Oriente a comprar los manuscritos, labor que considera que también podría hacer Casiri (Sarmiento, Sobre los códices, 56), recuperando políticas de importación de códices que ya había practicado Felipe II (Andrés, Descripción), y también, tendremos ocasión de volver a referirnos a ello, a través de las traducciones de los manuscritos.

El proteccionismo sobre el patrimonio librario español que Sarmiento reivindica en tantos textos, también en estos informes a Rávago, no le libra del deseo etnocentrista de querer acumular manuscritos orientales en las bibliotecas españolas a costa de "importar" estas piezas desde sus países de origen. Desde luego, era esta una práctica común en las más importantes bibliotecas europeas del momento, y no sólo en relación con los manuscritos orientales, pues importantes figuras de la orden benedictina como Mabillon en sus viajes por Italia y Alemania habían sido comisionados para la adquisición de libros y manuscritos con destino a la Biblioteca Real francesa.

Será en esas bibliotecas europeas en las que se base Sarmiento al indicar al confesor real lo bien que realizaban estos trabajos de "importación" los maronitas y los jesuitas, gracias a los cuales muchas joyas literarias árabes y chinas habían ingresado en la Biblioteca Vaticana y en la Real de Paris. Con admiración reseña la entrada de muchos libros chinos en la última biblioteca citada, enviados por los 
misioneros jesuitas como el P. Le Gac ${ }^{5}$, el catálogo que se publicó de ellos, los extractos de 389 títulos, y la edición de una gramática china "con sus mismos caracteres Geroglíphicos" (Sarmiento, Sobre los códices, 57), refiriéndose a las obras de Étienne Fourmont ${ }^{6}$ publicadas en 1737 y 1742.

En parte estos trabajos de importación fueron realizados por los maronitas: en el Vaticano habían sido los alumnos del Colegio maronita los encargados de la adquisición de los códices en Oriente, destacando el papel de Assemani, mientras que en Francia lo habían hecho sus cónsules, contando con la colaboración de los maronitas de Alepo o Monte Líbano, quienes nutrieron la Biblioteca Real, si bien los trabajos de catalogación de ésta fueron llevados adelante por los maronitas (Gemayel). Pero en Francia esta vía de ingreso se impulsó con la participación de eruditos y filólogos, como señala Sarmiento (Sobre los códices, 57).

"No hace mucho que por orden de Luys XV pasaron a la Grecia, Constantinopla y Lebante algunos Doctísimos Académicos de Paris con el mismo fin de comprar medallas, M.S $S^{\text {tos }}$ y otras Antigüedades, $y$ volvieron cargados de mucho bueno. Los Yngleses y Holandeses, que navegan al Lebante y al Oriente, rara vez vuelven sin traher algunos M.S. ${ }^{\text {tos }}$. orientales... “

Se refería aquí Sarmiento a la larga tradición de viajes arqueológicos, ligados a la busca de manuscritos y medallas para las bibliotecas, aunque eran los primeros el objetivo fundamental del viaje ${ }^{7}$. Estas misiones se habían iniciado con carácter particular en el siglo XVI y de forma oficial a comienzos del siglo XVII, citando Sarmiento las realizadas por Vansleb (1635-1679) y Paul Lucas (1664-1738) ${ }^{8}$. Los

${ }^{5}$ Étienne Le Gac (1671-1738) fue superior jesuita en la misión de Carnate, en el Sur de la India, proporcionando manuscritos indios a las bibliotecas del Colegio Louis-le-Grand y a la Real de Paris. A esta última llegaron procedentes de esta misión 160 manuscritos, que constituyen el núcleo de la actual colección de manuscritos sáncritos e indios de la Biblioteca Nacional de Paris.

6 Étienne Fourmont (1683-1745), orientalista francés miembro de la Académie des Inscriptions et Belles-Lettres. Es uno de los primeros estudiosos franceses que realiza un estudio del chino.

7 "Il n'est nécessaire d'avertir lesdits sieurs Sevin et Fourmont que, quoyque l'objet principal de leur voyage soit la recherche et l'acquisition des livres pour la Bibliothèque de Sa Majesté, ils ne doivent pas négliger ce qu'ils pourront trouver de médailles de toute espèce, qui pourroient manquer à son Cabinet, comme aussy d'apporter, s'il est possible, d'anciennes inscriptions, ou du moins d'en tirer des copies figurées exactement, en désignant présisément les lieux où elles se trouvent." (Mémoire du Roy pour servir d'instruction aux sieurs Sevin et Fourmont, de l'Académie des inscriptions et belles-lettres (1728), reprod. en Omont, 1, 438).

${ }^{8}$ Vansleb o Vansleben, dominico alemán, colaborador de la edición de la Políglota de Walton, viajó a distintos lugares de Oriente (Trípolí, Alepo, Damasco) y especialmente a Egipto, donde estuvo los años 1672-1673, adquiriendo manuscritos y medallas para la 
viajes fueron impulsados en época de Luis XV por Jean-Paul Bignon ${ }^{9}$, bibliotecario real, que proporcionaba a los viajeros detalladas instrucciones sobre los lugares que debían visitar y las piezas a que debían estar atentos, en lo posible para adquirirlas y si no para copiarlas (Omont, 1902: 1, 438). Los mejores exponentes de esta política en el período a que hace referencia Sarmiento fueron los viajes realizados por miembros de la Académie des Inscriptions et Belles-Lettres, como el de 1728 de François Sévin ${ }^{10}$ y Michel Fourmont ${ }^{11}$ que supusieron a esta biblioteca cerca de 400 manuscritos orientales y 125 griegos; y que serían continuados por Jean $\mathrm{Otter}^{12}$ en Ispahan entre 1737 y 1739, Pierre Armain $^{13}$ en Constantinopla en 1748, etc. También en Inglaterra se enviaron comisionados a Oriente con la misma finalidad. Entre ellos hay que destacar al orientalista Edward Pocock ${ }^{14}$ que permaneció varios años en Alepo enviado por el ministro William Laud.

Sin embargo, la propuesta de adquirir manuscritos en Oriente parece no haber tenido éxito en España hasta bien avanzado el siglo XIX, aunque sí se realizaron mayores esfuerzos en la copia y traducciones de manuscritos árabes en la Biblioteca Real, labor que llevaron adelante durante la dirección de Santander los maronitas Casiri, Pablo Elías Hodar, Antonio Bahna (Guillén Robles, 1889: 5), Juan Amón de San Juan. Casiri hizo la

Biblioteca Real. Paul Lucas, comerciante, naturalista y anticuario, realizó distintos viajes a Oriente al servicio de Luis XIV, aportando a su Biblioteca y Gabinete importantes colecciones de manuscritos, medallas, y otros objetos preciosos. Colaboró en 1736 en la ordenación de las medallas de la Biblioteca Real, junto con Juan de Iriarte. Murió en Madrid en 1738. (García Ejarque, 509-10). (Omont, Henri: Missions archéologiques..., 1, 317-82).

9 Jean Paul Bignon (1662-1743), bibliotecario de Luis XIV desde 1718, organizó los departamentos de la Biblioteca Real y el depósito legal y es el primero en abrir esta biblioteca al público. Gracias a su impulso, la Biblioteca Real incrementa notablemente sus manuscritos, medallas y objetos antiguos.

${ }^{10}$ François Sevin (1682-1741) viajó con Fourmont a Constantinopla, y fue nombrado en 1732 conservador de los manuscritos en la Biblioteca Real, redactando los primeros volúmenes del Catálogo de los manuscritos orientales y griegos de la Biblioteca del Rey.

${ }^{11}$ Michel Fourmont (1690-1746), hermano de Étienne Fourmont, profesor de siríaco en el Colegio de Francia, viajó con Sevin a Grecia y Turquía, desde donde envió numerosas copias de inscripciones griegas y manuscritos. Redactó un Catalogo de los manuscritos griegos de los Monasterios de Néa Moni y San Minas.

${ }^{12}$ El filólogo Jean Otter (1709-1748) fue uno de los agentes de Bignon en Oriente para incrementar las colecciones de antigüedades, siendo nombrado posteriormente intérprete real. Escribió Voyage en Tourquie et en Perse (1748).

${ }^{13}$ Pierre Armain fue intérprete real para las lenguas turca y persa. En 1722 visita Egipto desde donde envía manuscritos árabes y persas para la Biblioteca Real. En 1747 se traslada a Constantinopla con encargo de Bignon de examinar los progresos de la imprenta turca establecida en esta ciudad en 1726, y redacta un catálogo de libros turcos impresos en Constantinopla.

${ }^{14}$ Edward Pocock (1604-1691) fue un orientalista y teólogo inglés, profesor de árabe y hebreo en la Universidad de Oxford. A partir de 1630 permaneció cinco años en Alepo y de nuevo volvió a esta ciudad en 1637. En estas estancias adquirió manuscritos orientales para la Bodleian Library. 
traducción latina de un códice árabe titulado Sol de la sabiduría que dedicó a Rávago (Banqueri, 1802: 1, 13), y la copia y traducción del manuscrito arábigo con la colección de cánones Colección Hispana Sistemática (Soto Pérez, 1985: 148). También entraron durante estos años algunos manuscritos árabes que formaron parte de adquisiciones del momento: en 1752 Martínez Pingarrón refiere a Mayáns: "Mi bibliothecario mayor ha comprado de entre unos manuscritos, que tenía Mena, una copia manuscrita de la Historia del moro Rasis con algunas notas de letra de Dn. Nicolás Antonio" (Mayans i Siscar, Epistolario, 7, 1, 400-02). En otras ocasiones fueron las adquisiciones de bibliotecas las que aportaron algunos manuscritos árabes, tal como los existentes en el fondo de la casa condal de Miranda, adquirida en 1757 al librero Mena (Andrés, 1979).

Sarmiento, a quien no podían dejar de presentársele algunos problemas con los códices de la "secta falsa de Mahoma", se enfrentaba al hecho de que como obras prohibidas por los índices inquisitoriales no podían usarse ni publicarse tales códices, y por tanto para qué catalogarlos. Aún así no pueden ser considerados por el benedictino como totalmente inútiles. En primer lugar servían para refutar las doctrinas coránicas escribiendo "alguna impugnación en Arábigo, para esparcirla entre los Mahometanos", tal y como hizo Marraccio. Pero la segunda utilidad que les encuentra Sarmiento se relaciona directamente con el incremento de las colecciones, ya que propone un intercambio "a la moda de los libreros", tantos pliegos por tantos otros "sin apreciar ni despreciar los asumptos de los mismos pliegos escritos" (Sarmiento, Sobre los códices, 74). Este sistema de trueques fue muy empleado en el siglo XVIII en las bibliotecas institucionales, y no era desconocido en las de la Congregación de San Benito de Valladolid. En cuanto a su uso por los libreros, parece referirse al intercambio de los libros que editaban, una práctica atestiguada en la correspondencia de Mena (Mayans i Siscar, Epistolario, 12, 501). Ahora para esta labor de trueque, Sarmiento propone como biblioteca para el intercambio la del Rey de Marruecos y como agentes a las órdenes religiosas que se dedicaban a la redención de cautivos. Pero el propio trueque propuesto en este caso tiene un claro objetivo de recuperación del patrimonio nacional, ya que supone que la biblioteca del Rey de Marruecos tendrá muchos códices "de cosas tocantes a nuestra España" inexistentes en el Escorial, y la biblioteca del monasterio manuscritos que tratan asuntos mahometanos que "acá no hacen falta" y que la biblioteca de aquel Rey no posee. En todo caso, algunos trueques ya habían tenido lugar antes de la propuesta sarmentina, permitiendo incorporar algunos fondos árabes a la Biblioteca Real. Tal es el caso del intercambio realizado por Iriarte con la biblioteca del convento de San Vicente de los dominicos de Plasencia, donde a cambio de algunos libros modernos, se retiraron manuscritos e impresos procedentes de la biblioteca de García Loaisa, entre ellos libros en lengua hebrea, griega y árabe, aunque no se hizo inventario de los mismos (García Sánchez, 1993: 83). 


\subsection{LA CATALOGACIÓN DE MANUSCRITOS}

Pero si la importación de manuscritos de Oriente no parece plantear a Sarmiento ningún problema, como señalamos, sí le preocupaba la salida de manuscritos de España. Ya en 1743 en las Reflexiones literarias había mostrado su preocupación por la exportación de estas piezas y la necesidad de poseer un catálogo de ellas que evitase su salida de España.

Ahora, cuando se dirige a Rávago en febrero de 1750 para justificar su demanda de que se lleve a cabo la catalogación de los manuscritos de las bibliotecas españolas, Sarmiento comienza apelando a la Bibliotheca Bibliothecarum del benedictino Montfaucon, compilación de los catálogos de manuscritos de las bibliotecas de Europa, en la que en la opinión de Fray Martín se encuentran los más importantes repertorios de ellas, a no ser el caso de España donde sólo se reseña un catálogo de manuscritos, fundamentalmente griegos, del Escorial. No dejará Sarmiento de señalar que entre esas bibliotecas europeas no faltan las de emperadores y reyes, una llamada a la emulación apelando al nacionalismo español, que será usado más de una vez en este texto.

La necesidad de elaborar estos catálogos, señala nuestro benedictino, reside en la utilidad que los manuscritos tienen en el avance de la ciencia, la construcción de la historia y el desarrollo económico y social del país, ya que en ellos residen las bases para el adelantamiento de la agricultura, la educación, la medicina, etc., etc. Esta importancia justifica la necesidad de saber cuántos y cuáles son y en dónde se conservan. $\mathrm{Y}$ además ninguna obra inédita o reimpresión corregida de escritores antiguos podrá realizarse con seriedad, si a partir de los catálogos de manuscritos no se cotejan las diferentes copias existentes en las bibliotecas. En opinión de Sarmiento, las dificultades para colacionar e incluso para ver los códices son notorias en los archivos españoles.

Pero, como señalamos, Sarmiento no elude descender a terrenos más operativos, y así en las opiniones enviadas a petición de Rávago sobre el primer borrador del índice de Casiri, encontramos una propuesta sobre la catalogación de manuscritos. No era la primera vez que Sarmiento había trabajado sobre la catalogación de los mismos, pues había catalogado en 1726 y 1727 el archivo y la biblioteca de la catedral de Toledo, junto con Diego Mecolaeta, y en 1743 había propuesto la elaboración de un catálogo de manuscritos, que hoy denominaríamos colectivo, con objeto de evitar en puertos y aduanas la salida de estas obras de España.

Sin duda tal catalogación tenía una amplia tradición, pero los catálogos realizados en la Edad Media poseían fundamentalmente un carácter de inventarios patrimoniales. En el siglo XVI este enfoque patrimonial no había desaparecido totalmente, aunque se realizan entonces importantes trabajos, como los de la propia biblioteca del Escorial de Arias Montano o la Bibliotheca manuscripta graeca de Antonio Agustín. Pero no encontramos todavía ningún intento de sistematización de la descripción. No será hasta finales del siglo XVII cuando se comience a plantear la 
redacción de noticias bibliográficas con finalidad científica, siguiendo los esfuerzos de normalización descriptiva de las ciencias naturales y el desarrollo de la filología y de las ciencias auxiliares de la historia. En los estantes de la biblioteca de Sarmiento figuraban dos obras cumbre en la materia: la Bibliotheca Coisliniana olim Segueriana sive manuscriptorum omnium graecorum quae in ea continentur accurata descriptio (1715) y la Bibliotheca Bibliothecarum manuscriptorum nova (1739), ambas primeras ediciones de las obras de Montfaucon, consideradas punto de partida de la moderna ciencia catalográfica (Petrucci, 1995: 16-17), que se desarrollaba al mismo tiempo que la paleografía y la diplomática. Como en otros muchos temas nuestro autor sigue con atención el trabajo realizado en Francia por los benedictinos de la Congregación de Saint-Maur.

En 1750 Casiri había ya elaborado un Índice de los manuscritos árabes de la Biblioteca del Escorial, que debe tratarse del Index librorum manuscriptorum orientalium (Justel, 230), manuscrito conservado hoy en esta biblioteca, y del cual bien el original, bien una copia fue sometido por Rávago a la opinión de Sarmiento, como hemos señalado. Casiri parece haber corregido el índice, como muestran las anotaciones marginales. Pero ni el contenido de la descripción bibliográfica ni la disposición alfabética de autores coincide con la opción tomada en la edición impresa del catálogo, edición que Sarmiento considera imprescindible. Todo parece indicar que Rávago, influido por Sarmiento, en 1749 hace el encargo del índice como un instrumento para el uso de la biblioteca, pero Sarmiento, vista la primera redacción, recomienda que la descripción bibliográfica y la presentación se mejoren y además resalta la importancia de que se imprima, de lo que informa a Rávago. Le insiste sobre el valor de realizar los catálogos de los manuscritos, alabando la labor realizada por Casiri, el interés de su impresión y la necesidad de contar en ella con transcripciones del árabe para lo cual se requiere una imprenta que lo permita. Casiri vuelve al Escorial y lleva una nueva redacción del trabajo a la celda del benedictino, por indicación de Rávago, al cual le señala Sarmiento: "No necesito ser molesto para decir, que el gusto, que he tenido entonces en leer, y aplaudir los primeros trabajos, se me aumentó con exceso, leyendo los segundos por estar más circunstanciados" (Sarmiento, Sobre los códices, 69).

Por el primer informe a Rávago sabemos qué información bibliográfica, "circunstancias características de los códices", consideraba el benedictino que debía añadírsele al índice de Casiri y por tanto era conveniente, en su opinión, que el maronita volviese al Escorial y la anotase. Sarmiento considera imprescindibles una serie de campos para la descripción de los manuscritos árabes, pero no deja de señalar que tales campos también los introduciría él en la descripción de los manuscritos latinos. En este sentido hay que señalar las diferencias existentes entre los elementos de descripción ahora propuestos y los que más de 20 años antes había introducido para describir los códices toledanos. En la parte realizada por Sarmiento del catálogo de los manuscritos de Toledo (Sarmiento, Bibliotheca), se indica autor, título o breve descripción del contenido, fecha, lengua, soporte, 
signatura y tamaño. Si el códice reúne distintas obras, realiza una descripción pormenorizada de las mismas. Ahora, en 1750, amplía la información en la descripción, y si bien no reproduce exactamente los campos contemplados por Montfaucon, y tampoco los ordena igual, coincide en el cuidado en la datación, en la indicación de autores y títulos y en la transcripción del inicio de cada texto, en la identificación de la grafía y la indicación de la foliación, y en la elaboración de un índice de autores, un conjunto de información bibliográfica fundamental a la hora de identificar el manuscrito.

Los datos bibliográficos que Sarmiento cree que deben añadirse al índice de Casiri son agrupados por el benedictino en doce campos. El primero de estos campos se refiere a la identificación del ejemplar en la biblioteca, la signatura, "Número y lugar" en sus palabras, o lo que es lo mismo número de orden y estante. Los cuatro campos siguientes se relacionan con la descripción material de los manuscritos: "marca" del papel o tamaño, foliación o número de pliegos, soporte de escritura, y tipo de caracteres (orientales, africanos, cúficos, con puntos o sin puntos, etc.).

En los campos siguientes propone Sarmiento entrar en la descripción interna del manuscrito, indicando idioma; autor (nombre "por entero", primero en caracteres árabes, y después en latinos); título, transcripto de la misma forma que el autor; incipit y explicit, en caracteres árabes, y con traducción, dato en el que insistirá con objeto de hacer el cotejo con otros catálogos; fecha, también transcrita, e indicando además si el lugar y la fecha corresponden a cuando y donde se copió o transcribió; materia, "ciencia, materia, o asumpto de que trata y un ligero extracto de sus divisiones"; y finalmente la "crítica", un juicio del autor, de su estilo y de la obra, lo que se habría de hacer si trata de España "con la extensión que cupiere".

La Bibliotheca Arabico-Hispana Escurialensis de Casiri adopta algunos de los criterios de la descripción bibliográfica propuesta por Sarmiento, y mejora considerablemente el primer inventario realizado. En el texto latino aparece un número de orden dentro del catálogo. En cuanto a la descripción indica tamaño (dentro de cada clase, los códices se agrupan por tamaño), letra del manuscrito, material de escritura solo en el caso del pergamino, nombre y patria del copista o autor, volúmenes cuando son varios, fecha (hégira y era cristiana), foliación en caso de que la posea el manuscrito, contenido, título y autor, biblioteca de la que procede el códice, notas y extractos cuando se considera conveniente. Tales notas nos indican con frecuencia la bibliografía con que Casiri realizó su trabajo, tal como el catálogo de los manuscritos orientales de la Biblioteca Real de Paris o la obra de Herbelot, así como diferentes fuentes árabes. En el texto árabe los titulillos latinos de los campos se limitan a Auctor, Titulus et Auctor, Initium, e Finis para cada una de las obras incluidas en el códice que se describe. El propio Casiri indica las razones por las que no refleja algunos campos como la foliación, que sí estaban en la propuesta de Sarmiento, ya que requerían un trabajo de foliación 
previa de los manuscritos, a excepción de los que ya estaban previamente foliados donde sí lo indica (Casiri, 1760-1790: 1, 8).

No deja de advertir Sarmiento la necesidad de revisar los códices para comprobar si incluyen varias obras de diferentes autores con objeto de describir los distintos textos en el Índice, pero sin multiplicar innecesariamente el número de registros. Finalmente añade la forma de disponer los registros en el catálogo, señalando que puede ser alfabético o mejor por materias con índice final de autores, tal y como había propuesto Montfaucon y como señala el propio Sarmiento se hizo en el catálogo de manuscritos arábigos de la Biblioteca Real de Francia. En realidad el catálogo parisino de los códices orientales (Catalogus), redactado por Étienne Fourmont et Guillaume de Villefroy, estaba ordenado por lenguas, y dentro de los manuscritos árabes separaba los de autores cristianos y mahometanos. Después de esta distinción la ordenación era por materias y dentro de ellas por tamaños. Pero en él la descripción de cada uno de los manuscritos era considerablemente más exigua que la propuesta por Sarmiento, limitándose a un extracto del contenido en latín y a la fecha cuando la datación estaba en el códice.

También aquí Casiri atiende las recomendaciones de Sarmiento, lo que le fue señalado por el bibliotecario Santander, según él mismo indica (Casiri, 1, 3): en su visita al Escorial en 1752 examina los códices de nuevo, los ordena y organiza por clases (Casiri, 1760-1790: 1, 3). En la redacción del Índice realizado en su primer viaje seguía el orden topográfico de los manuscritos, un modelo catálogoinventario que llevaba siglos predominando en las bibliotecas, aunque lentamente se iba introduciendo la necesidad de distintos puntos de acceso a la información bibliográfica. Martínez Pingarrón en 1753 informa a Mayans de los progresos de la obra, señalando: “...Al principio, esto es antes que fuéramos al Escorial, estava buena, pero sin el mejor méthodo, pues no tenía otro que el que avían presentado los códices, conforme se avían puesto en las manos; ahora va por facultades, con los principios i fines de las obras, con toda crítica e historia" (Mayans i Siscar, Epistolario, 7, 1, 416-18).

Ahora la ordenación de la Bibliotheca de Casiri pasa a ser temática, y dentro de cada clase por tamaños. Las clases en que se distribuyen los manuscritos son las siguientes: Grammatici, Rethorici, Poetici, Philolologici et miscellanei, Lexicographi, Philosophici, Ethici \& Politici, Medici, Ad Historiam Naturalem pertinentes, Mathematici, Ad Jurisprudentiam pertinentes, Theologici, Geographici, e Historici, estos dos últimos grupos constituyendo el volumen segundo de la obra impresa. En la clase Historia dentro del manuscrito 1649 incluye Casiri el texto de Sarmiento sobre el origen de la voz Escorial (Casiri, 1760-1790: 2, 61-4), en cuya etimología divergían los dos autores, ya que el primero había dado un origen arábigo a la voz en el primer tomo de su Bibliotheca (Casiri, 1760-1790: 1, 20), mientras el segundo la hace derivar del latín Esculus.

En los años siguientes a la propuesta de Sarmiento se producen determinados trabajos, que indican hasta qué punto interesaba un nuevo tratamiento de los 
manuscritos en las bibliotecas y la normalización de su catalogación. En 1761 las Constituciones de la Real Biblioteca de Madrid requieren que los manuscritos se coloquen en pieza aparte y se describan en catálogos separados ${ }^{15}$, lo que se trasladará a las Constituciones de las bibliotecas universitarias en los años posteriores. Pocos años después las instrucciones dadas para realizar los inventarios de libros y papeles de los jesuitas expulsos muestran en qué medida se había hecho presente la necesidad de un tratamiento específico para los manuscritos (Colección).

En 1762 Juan de Iriarte presenta la primera Instrucción para formar el Índice de manuscritos de la Real Bibliotheca (Vázquez de Parga), trufada de aspectos prácticos dirigidos al análisis de quien había de describirlos, pero no podía ser a un tiempo especialista en todo tipo de manuscritos, de cualquier tema, escritura, lengua y fecha. En cualquier caso el cuidado de la descripción bibliográfica es mucho mayor cuando el catálogo ha de imprimirse, y así cuando en 1769 Iriarte publica su Regiae Bibliothecae Matritensis códices graeci manuscripti, los datos bibliográficos incluidos son similares a los propuestos por Sarmiento, y mucho más detallados que los incluidos en su Instrucción (Sánchez Mariana, 1993: 216).

\subsection{UN PROGRAMA DE EDICIÓN DE TEXTOS ÁRABES}

En sus cartas a Rávago Sarmiento insistirá en la traducción y edición de muchos códices arábigos de todas las materias, empezando por los referentes a España atendiendo "...a la visible utilidad que se seguiría de traducirlos" (Sarmiento, Sobre los códices, 59). Pero además, como "tan poco me cuesta hacer de este género de propuestas", piensa que se deberían llevar adelante una serie de síntesis de los distintos códices en las diversas materias. Sarmiento en otras ocasiones, como en el Catálogo para formar una librería curiosa (1748), había expresado con claridad este ideal enciclopédico: la imposibilidad de una biblioteca exhaustiva obliga a pensar en una biblioteca selecta, una representación de todos los libros, en fin en la síntesis enciclopédica. Esta síntesis en su propuesta a Rávago (Sarmiento, Sobre los códices, 79) se concreta en 12 grandes enciclopedias temáticas:

1. Gramática Arábico-Hispana Completa

2. Diccionario Arábico-Hispano-Latino completo

15 “Los libros y papeles manuscritos tendrán su índice general alfabético, así de los autores, como de materias, compuesto con mucha mayor expresión e individualidad que el de los libros impresos...; y cuidará mucho el bibliotecario mayor de que este índice, por su mucha importancia, se haga con la debida exactitud crítica" (Constituciones de la Real Biblioteca, 1761, transcr. en GARCÍA EJARQUE, 122). 
3. Historia Literaria Arábico-Hispana en latín

4. Geografía Arábico-Hispana en latín

5. Cronologia Arábico-Hispana en latín

6. Agricultura Arábico-Hispana en castellano

7. Botánica Arábico-Hispana en castellano

8. Historia natural arábico-Hispana en castellano

9. Medicina selecta Arábico-Hispana en latín

10. Astronomía arábico-hispana en latín

11. Matemáticas (y artes) Arábico-Hispana en castellano

12. Historia Civil Arábico-Hispana en castellano

La elección de la lengua de traducción está en función del público al que Sarmiento cree que se deben dirigir las obras: en castellano para "utilidad de la multitud", latín para "utilidad de la República literaria". Naturalmente gramática y diccionario habían de tener el árabe correspondiente, y todas las demás un índice de voces arábigas en caracteres arábigos de lugares, autores, personas y mixtos.

Pero para que pudiesen editarse e incorporarse los textos árabes, para empezar en la edición del propio catálogo de Casiri, era preciso contar con una imprenta que tuviese los correspondientes tipos: "En Italia, Francia, Inglaterra, Holanda, Alemania, etc. ha habido y hay imprentas arábigas;...en ninguna otra parte más que en España se necesitan aquellas imprentas". Esto escribía Sarmiento a Casiri en 1749 durante su primera estancia en la biblioteca del Escorial (Banqueri,1802: 22-3). Esta imprenta permitiría reconstruir los 500 años de historia que median entre el rey don Rodrigo y Don Rodrigo Jiménez de Rada. "Los que han ojeado, aunque solo sea de paso, como yo, la citada Bibliotheca oriental, de Herbelot y la Bibliotheca Rabinica del $\mathrm{P}^{\mathrm{e}}$ Bartoloccio, se aturdiran de ver tanta multitud de Autores españoles en ellas, assi Mahometanos como Judios, que escribieron en aquellos siglos $9^{\circ}, 10^{\circ}, 11^{\circ}, 12^{\circ}, 13^{\circ}$ " (Sarmiento, Sobre los códices, 56v). Sarmiento le recuerda a Rávago la importancia de la imprenta arábiga de los Medicis y la de la congregación de Propaganda Fide en Roma, la instalada por Erpenio en Leiden, etc.

Efectivamente las imprentas árabes habían tenido cierto desarrollo en distintos países de Europa, especialmente en Italia, donde se habían instalado en Venecia y Génova, dos ciudades con importantes lazos comerciales con Oriente. A lo largo de los siglos XVI y XVII Italia pondrá en marcha distintos proyectos de prensas árabes. En 1556 el Colegio jesuita de Roma instala una prensa árabe para apoyo a las misiones. Pero sin duda, es la creada por Fernando de Medicis en 1584, la Typographia Medicea Externarum, al frente de la cual estaría hasta su desaparición en 1610 el orientalista Giovanni Battista Raimondi, la más importante de ellas. Su producción, además de textos religiosos y gramáticas árabes, comprendía también obras de Avicena, Euclides, etc. y una versión latina de la geografía del Nubiense. Alrededor de 1614 comienza a trabajar en Roma la 
imprenta del Colegio maronita que cesará su actividad hacia 1625 , y al año siguiente comienza su actividad la Tipografía de la Congregación Propaganda Fide, que años más tarde adquirirá los caracteres del Colegio maronita.

Frente a esta temprana aparición de la imprenta con caracteres árabes en Italia, también en Francia ${ }^{16}$ y otros lugares, aunque con menor continuidad, en España la introducción de la tipografía árabe es tardía. Con muy pocas excepciones los fundidores españoles se habían servido de matrices de Holanda, Francia, Italia, etc. Cuando en 1751 Casiri y Campomanes traducen dos capítulos del Tratado de Agricultura de Ibn al-'Awwam ${ }^{17}$ para añadirlo a la edición de la obra de Duhamel de Monceau (Duhamel), difusor del método de Tull en España, elaboran una lista de voces arábigas para cuya impresión hubo de traerse una fundición de letra arábiga de Holanda. La obra fue impresa en la imprenta del Mercurio, que desde 1745 dirigía Miguel Aoiz, traductor también del texto de Duhamel, siendo el impresor José de Orga, aunque el apéndice de las voces arábigas fue impreso por Antonio Pérez de Soto (Soto Pérez, 1985: 149).

Parece probable que con estos mismos caracteres se imprimiese la hoja de la Bibliotheca de Casiri que Sarmiento dice haber visto en julio de 1751:

Esta hoja está impresa Arabico-Latina, y en Madrid, lo que me ha causado un singularísimo gozo, constándome que separando un mal Alphabeto Arabigo, que se halla en la Gramatica del P. Alcalá, jamás se ha visto hasta hoy en España impresión alguna de Caracteres Arábigos (Sarmiento, Sobre los códices, 83).

En ese mismo mes, Martínez Pingarrón señala que la fundición de caracteres árabigos ha llegado a Madrid y el impresor está formando la prueba de la Bibliotheca de Casiri. Y en octubre de ese año medio pliego "que ha servido de modelo para la impresión" es enviado por Casiri y Martínez Pingarrón a Mayans (Mayans i Siscar, 2006: 449-51).

${ }^{16}$ Sarmiento señala que en los años 30 no debía de existir imprenta con caracteres arábigos en Francia, como mostraba el hecho de que el catálogo de los manuscritos de la Biblioteca Real se hubiese impreso en caracteres latinos en 1739, como no la había en 1716 cuando se imprimieron las liturgias orientales de Renaudot, aunque lo hubiese intentado Colbert poco antes de su muerte.

17 De esta traducción espera Sarmiento que se sigan providencias para mejorar la producción agrícola, pero además que se consigan otras cosas, sobre todo si se emplean los caracteres arábigos en el vocabulario de frutos, granos, arboles, hierbas, animales, lugares, autores, ríos y terrenos: "De este modo se ilustrará mucho la Geografía, la Historia natural y nuestra lengua, y en especial el Dialecto Andaluz, que tanto abunda de voces Arábigas, cuyo origen nos es incognito y obscuro" (Sarmiento, Sobre los códices, 70v.). 
Ya unos años antes, en las Reflexiones literarias, Sarmiento había puesto de relieve la necesidad de contar con una Imprenta Real que se había de ubicar en el nuevo edificio que propone para la Biblioteca Real, y no contentarse a "la miseria de una, o de otra fundición", sino traer de Roma, Holanda o Inglaterra, etc. las matrices de caracteres latinos, griegos, hebreos, arábigos, y una o dos fundiciones de cada lengua (Sarmiento, Sobre los códices, 68). La Biblioteca Real, comenta ahora en 1750 a Rávago, debe ser también palacio o casa de ejercicios donde los miembros de diferentes Academias puedan llevar adelante el programa de edición, consultando las obras de la biblioteca y siguiendo los trabajos de impresión. El mercado para estos impresos no duda Sarmiento en considerar que lo constituirían las bibliotecas públicas que en 1743 había propuesto que se creasen en todos los lugares que pasasen de mil vecinos. Y ya en ese año no dudaba de que la creación de una Imprenta Real estimularía la creación de otras imprentas públicas en España, siguiendo el modelo de la Real (Sarmiento, Reflexiones, 94).

Efectivamente la Imprenta Real de Madrid acabaría llevando adelante unas décadas más tarde algunos de los trabajos de recuperación de los textos manuscritos, entre los que aquí destacaremos la edición bilingüe español/árabe de Ibn al-'Awwam El libro de la agricultura, en el que su traductor, José Antonio Banqueri ya trabajaba en 1783, aunque no se editará hasta 1802 , o la versión también bilingüe hecha por José Antonio Conde de la geografía de España del Nubiense, Descripción de España de Xerif Aledris (Al-Idrīīi), editada en 1799, textos ambos que Sarmiento valoraba especialmente en Sobre los Códices.

\subsection{EDICIÓN E IMPRESIÓN DE LA BIBLIOTHECA ARABICO- HISPANA}

La transcripción en árabe de los datos bibliográficos de los manuscritos que incorpora la Bibliotheca y que no utilizaba el catálogo de Paris, parece inspirarse en la insistencia sarmentina en evitar los problemas derivados de las diferencias con que los distintos países europeos transliteran los textos árabes. En sus informes a Rávago, el benedictino se referirá a sus lecturas de juventud, de las que había tomado apuntes, y resaltará el valor de la obra de Herbelot, en su opinión el mejor libro en temas orientales, del que destaca que se realizó en exclusiva con las fuentes manuscritas de la Biblioteca Real de París, pero en el que lamenta la transcripción al francés de los nombres de personas, lugares y títulos porque "cada nación europea los desfigura a su modo".

La necesidad de introducir la lengua árabe la repite Sarmiento en la carta a Casiri ya citada, donde, a la vista de la prueba impresa de la Bibliotheca, realiza una serie de recomendaciones sobre la edición, haciendo referencia a la existencia de distintos pareceres en cuanto a la disposición de los textos latinos y arábigos en la obra, que el benedictino prefiere en dos columnas, resaltando el carácter representativo de las magnas colecciones de la monarquía española ante las cortes 
europeas. Un carácter que aconseja se aumente la tirada a 3 resmas para cada pliego, ya que a pocos que se regalen o vendan, quedarían muy escasos ejemplares de una obra que sólo desde el apoyo institucional puede ser editada, ya que ningún librero español puede reimprimirla en árabe dados sus costes y la imposibilidad de encontrar un corrector para la reimpresión (Sarmiento, Sobre los códices, 83-4).

Además recomienda a Casiri sangrar los autores, tanto en el texto latino como en el árabe, para una más fácil lectura de los presentes en el catálogo, y hasta la disposición de columnas, márgenes y sangrados sobre el papel de marquilla es objeto de su atención y medidas. Propone también que en la columna árabe Casiri introduzca todos los nombres propios de personas, geográficos, del mundo natural, especialmente cuando éstos tienen relación con España, los títulos de la obra, y si es anónima la primera frase con que comienza y la última con que finaliza. La datación comprenderá día y mes de la hégira, para facilitar la correspondencia con los años. Nombres propios y textos que se escribirán también en la columna latina en letra cursiva. Hasta los signos ortográficos son revisados por Sarmiento en la carta. Junto a algunas indicaciones en relación a la disposición de las disertaciones que acompañan el catálogo, la carta sarmentina finaliza advirtiendo que la expresión Arabico-Hispana no le parece la más adecuada, y que hubiese preferido Arabico-Latina.

Aunque la Biblioteca Real de Madrid había comenzado muy pronto a editar algunas obras (García Cuadrado; Montalbán Jiménez, 2007), y su papel como autor o editor literario se recogerá claramente en cédula de 1778 (Carlos III, 33948), junto al de las Universidades, Academias y Sociedades, es en sus segundas Constituciones de 1761 cuando aparece recogido su papel editor, aunque se haga indirectamente, como ocurre en su Capítulo 1, artículo 6, donde al fijar el presupuesto de la biblioteca, después de otras cantidades dirigidas a la adquisición de libros, medallas y antigüedades, se añade "y 20.000 para impresiones", o en el Capítulo 3, artículo 17, donde se señala que "hasta que se ponga en planta la Imprenta Real", el bibliotecario mayor podrá nombrar librero, encuadernador e impresor de la biblioteca. Entre los que desempeñaron este papel de impresores de la Biblioteca Real está Antonio Pérez de Soto, quien aparece en 1760 como impresor de los Reinos y de las Academias española y de la Historia, y unos años después, en 1768, como impresor de la Biblioteca Real.

Será Pérez de Soto quien imprima el primer volumen de la Bibliotheca de Casiri. La edición, presentada el año 1753 (Casiri, 1760-1790: 1, 4), veía la luz con privilegio otorgado a la Biblioteca Real en 1754, donde el bibliotecario Juan de Santander trabajaba para formar un obrador de fundición, con objeto de reunir una colección de punzones y matrices de producción española. Allí habían llegado por estos años matrices procedentes de distintos impresores que Pérez Soto va comprando. Y para la Bibliotheca el bibliotecario Santander informa al Rey en 1761 de que "Para la impresión de la Bibliotheca Arabico-Hispana hizo venir de Holanda varias fundiciones de caracteres árabes..." (García Ejarque, 155). Aunque 
el tomo 1 lleva fecha de 1760, al año siguiente todavía no se había distribuido como indica Pingarrón a Mayans (Mayans i Siscar, Epistolario, 7, 8, 245-47):

Su magestad quiere repartir por sí a las cortes $i$ ministros la Bibliotheca arabico-hispana. Se le han entregado una porción de egemplares $i$ se están encuadernando otros. Después entraremos los demás, en que entra Vmd., i luego (creo) que se venderán. Si el rei dispusiere otra cosa, avisaré a Vmd. que deve tener espera, como nosotros la tenemos. I no se pueden pedir al rei (ninguno otro la da) porque sólo ha dado a las personas reales $i$ no a los ministros, hasta hacer sus cumplidos en Italia, Francia etc.

La edición de este primer tomo, dado el prestigio que se reconocía al trabajo de Casiri, significó el punto de inflexión para llevar adelante importantes cambios en la Biblioteca Real, ya que es entonces cuando el bibliotecario mayor asume por completo la dirección del centro, inicia un importante programa de ediciones y alberga la Imprenta Real, sin que, sin embargo, se le adjudicase su vieja aspiración de que se le anexionasen las plazas de Intérpretes reales, al igual que ocurría en la Biblioteca Nacional de París (Fernández, 1996: 126-27).

Aunque el tomo segundo de la Bibliotheca parece que se había finalizado en 1763 , no se editará hasta 1770 , en opinión de José Cebrián porque el bibliotecario Santander quería que saliese antes el catálogo de los manuscritos griegos de Iriarte, por el peso político de este en la corte (Cebrián, 1997: 125). El tomo, además del catálogo de los códices geográficos e históricos, incluye un índice de nombres propios, realizado a instancias de Santander, por los escribientes de la Biblioteca Real Francisco Moran, José Rodríguez de Castro y Juan Fernández de Oleo, ya que por entonces a Casiri se le había destinado a realizar la versión latina de los Cánones de la Iglesia Hispano-Árabe (Casiri, 1760-1790). Incluye también este tomo las anotaciones al conjunto de la obra que había realizado Gregorio Mayans, a instancias del bibliotecario Santander.

Se culminaba así una obra a la que Sarmiento había contribuido, que supondría un hito en el desarrollo de los estudios orientales en España, y que en gran medida participaba en su idea de que solo los trabajos colectivos podrían suponer un avance real en la construcción de una cultura española, factor fundamental en el desarrollo del nuevo estado nacional. La inclusión del primer volumen de la obra de Casiri entre sus libros de Historia literaria, dentro del apartado Vidas y Bibliotecas, y no entre los libros de Erudición oriental, muestra hasta qué punto entendía Sarmiento la Bibliotheca Arabico-Hispana Escurialensis como parte de los esfuerzos necesarios para el desarrollo de una historia cuya lengua y antigüedades eran la base de la elaboración de una identidad colectiva. 


\section{REFERENCIAS BIBLIOGRÁFICAS}

ANDRÉS, Gregorio de. "Los códices del conde de Miranda en la Biblioteca Nacional" Revista de Archivos, Bibliotecas y Museo, 1979, 82/4: 611-627.

ANDRÉS, Gregorio de. "Descripción sumaria de las colecciones de códices griegos del siglo XVI" Estudios Clásicos, 1972, 16: 219-228.

BANQUERI, Josep Antonio. Discurso preliminar, En IBN AL-AWWAM, Yahyá ibn Muhammad: Libro de Agricultura. Madrid: Imprenta Real, 1802: 1 CARLOS III, la Ilustración en las Imprentas Reales Madrid: Boletín Oficial del Estado, 1989

CASIRI, Miguel. Bibliotheca Arabico-Hispana Escurialensis... Madrid: Antonio Pérez de Soto, 1760-1770.

CATALOGUS codicum manuscriptorum Bibliothecae Regiae Paris: Tipographia Regia, 1739.

CEBRIÁN, José: Nicolás Antonio y la Ilustración española Kassel: Reichenberger, 1997.

COLECCIÓN general de las providencias...sobre el estrañamiento y ocupación de temporalidades de los regulares de la Compañia... Madrid: Imprenta Real de la Gaceta, 1767-1769.

DIDEROT, Denis, ed. Encyclopédie ou dictionnaire raisonnée... publié par M. Diderot,... et...par M. D'Alembert Paris: Le Breton, 1751-1765: T. 5.

DUHAMEL DE MONCEAU, Henri-Louis Tratado del cultivo de las tierras, según los principios de Mons. Tull...con ....un Apéndice...traducidos al español por...Miguel Casiri...y por...Pedro Rodríguez Campomanes...Madrid: Imprenta del Mercurio, 1751.

FERNÁNDEZ, Paz: "Expediente personal de Miguel Casiri en la Biblioteca Nacional" Al-Andalus Magreb, 1996, 4: 126-127.

FOURMONT, Etienne: Linguae sinarum mandarinicae hieroglyphicae grammatica dúplex...Paris: H.L. Guerin, 1742.

FOURMONT, Etienne: Meditationes sinicae... Paris: Joseph Bullot, 1737.

GARCÍA CUADRADO, Amparo; MONTALBÁN JIMÉNEZ, Juan Antonio. "Bibliotheca universal de la Polygraphia española: una impresión de 1738 realizada por la Biblioteca Real” Anales de Documentación, 2007, 10: 113-143. GARCÍA EJARQUE, Luis. La Real Biblioteca de S.M. y su personal (1712-1836). [Valencia]: Asociación de Amigos de la Biblioteca de Alejandría, 1997.

GARCÍA SÁNCHEZ, Justo. Análisis interno del manuscrito de la Biblioteca Nacional de Madrid Sign. 5.853 En Alvar Gómez de Castro: Vestales romanas...Ed. de Justo García Sánchez. Oviedo: Universidad, 1993.

GEMAYEL, Nasser. Les échanges culturels entre les maronites et l'Europe. Du College maronite de Rome (1584) au College de ${ }^{c}$ Ayn-Warqa (1789). Beyrouth: s.i., 1984.

GUILLÉN ROBLES, Francisco. Catálogo de los manuscritos árabes existentes en la Biblioteca Nacional de Madrid. Madrid, Impr. de Manuel Tello,1889. 
JUSTEL, Braulio. La Real Biblioteca del Escorial y sus manuscritos árabes: Sipnosis histórico-descriptiva. $2^{\mathrm{a}}$ ed. Madrid: Patrimonio Nacional, etc., 1987.

MAYANS I SISCAR, Gregorio. Epistolario. Edición de Antonio Mestre. Valencia: Diputación, 1972-2006.

MESTRE, Antonio. Historia, fueros y actitudes políticas. Mayans y la historiografia del XVIII. $2^{\mathrm{a}}$ ed. Valencia: Universidad, 2000.

OMONT, Henri. Missions archéologiques françaises en Orient au XVII et XVIII siècles. Paris, Imprimerie Nationale, 1902.

PETRUCCI, Armando. La descrizione del manoscritto. Storia, problemi, modelli. $3^{\text {a }}$ ristamp. Roma: La Nuova Italia Scientifica, 1995.

RAZÓN del juicio seguido en la ciudad de Granada... contra varios falsificadores de escrituras públicas, monumentos ... y libros de supuesta antigüedad. Madrid, Joachin Ibarra, 1781.

RIVIĖRE GÓMEZ, Aurora. Orientalismo y nacionalismo español: Estudios árabes y hebreos en la Universidad de Madrid (1843-1868) Madrid: Instituto Antonio de Nebrija de Estudios sobre la Universidad, 2000.

SÁNCHEZ MARIANA, Manuel. La catalogación de manuscritos en torno a la Biblioteca Real (1712-1836), En Gimeno Blay, Francisco M., ed. Erudición y discurso histórico: las instituciones europeas (s. XVIII-XIX) Valencia, Universitat, 1993: 213-22.

SARMIENTO, Martín. Bibliotheca de la Santa Yglesia de Toledo. Borrador de los libros que en ella registré el año de 1727... Colección Medinasidonia, T. 4: fol. 27-73. Mss.

SARMIENTO, Martín. Carta a Esteban de Terreros y Pando, 17 de enero de 1755, En Pensado, J. L.: Opúsculos lingüisticos gallegos del siglo XVIII. Vigo: Galaxia, 1974: 39-41.

SARMIENTO, Martín. Catálogo de los autores de quienes yo...tengo ad usum o todas sus obras o parte de ellas... 174-176-. Real Academia de la Historia, Mss. 9-9-5.

SARMIENTO, Martín. Catálogo de los pliègos, que yo Fray Martin Sarmiento,..., he escrito, de mi mano, pluma, y letra, sobre diferentes asuntos. 1767. Biblioteca Nacional de España, Mss. 17642.

SARMIENTO, Martín. Catálogo para formar una librería curiosa. Colección Medinasidonia, 6: fol. 107-181. Mss. Existe edición impresa, facsímil del texto publicado por el Semanario erudito, 5, 1787: 97-174: Catálogo de algunos libros curiosos y selectos, para la librería de algún particular, que desee comprar de tres á quatro mil tomos. Edición de Henrique Monteagudo. Noia: Toxosoutos, 2002.

SARMIENTO, Martín. Nota a dos Códices Arábigos que he visto, a 16 de Febrero de 1747. Colección Medinasidonia, T. 2: fol. 390-396v. Mss.

SARMIENTO, Martín. Pangrammaticon Lexicon sive clavis ómnium alphabetorum novum veterum...1718. Colección Medinasidonia, T. 1: fol. 47-64 v. Mss. 
SARMIENTO, Martín. Reflexiones literarias para una Biblioteca Real. A referencia cultural da ilustración española. Ed. y estudio de José Santos Puerto Santiago: Consello da Cultura Galega, 2002.

SARMIENTO, Martín. Sobre los códices orientales de la Real Biblioteca del Escorial. Colección Medinasidonia, T. 6, fol. 51r-105v. Mss.

SOTO PÉREZ, José Luis: Arabismo e ilustración: correspondencia literaria (1791-1803) de Fr. José Antonio Banqueri con Don Fr. Manuel del Cenáculo Vilas Boas obispo de Beja y arzobispo de Evora. Oviedo: Centro de Estudios del siglo XVIII, 1985.

VÁZQUEZ DE PARGA, Luís. Algunas noticias sobre la organización y primera catalogación de la Sección de Manuscritos de la Biblioteca Nacional, En Homenaje a Federico Navarro. Miscelánea de estudios dedicados a su memoria. Madrid: ANABAD, 1973: 435-445. 